\title{
The aggregate economic benefits of the National Cultivar Trials for Maize in South Africa with specific reference to the Highveld region
}

\section{Thula Dlamini}

Agricultural Research Council

email: dlaminits@arc.agric.za

\section{Frik Liebenberg}

University of Pretoria

Agricultural Economics, Extension and Rural Development

email: Frik.Liebenberg@up.ac.za

\begin{abstract}
The South African maize sector has been revolutionised from a system of production with low use of modern technologies to a leading maize producer in the African continent. That transformation is in part attributable to South Africa's investment in the national maize cultivar trials, which have facilitated the adoption and use of maize cultivars that are highly adapted to commercial farmer localities, causing considerable gains in yields. The economic value of the public investment in the trials remains unknown. This study uses experimental yields spanning 1977 - 2012 to attribute the influence of the national maize cultivar trials to maize yield improvement on farmer localities in the Highveld region of South Africa. Using attribution methods, the study estimates that $24.3 \mathrm{~kg}$ per hectare of extra maize yields accrued to commercial maize producers because of the national maize trials. The economic value of these investments was found to be R1.4billion (in 2012 currency values). The study estimates that South Africa received R37 of benefit for every rand invested by the Agricultural Research Council (ARC) in the trials.
\end{abstract}

Keywords: maize cultivar trials, economic benefits, agricultural research and development, South Africa, ARC.

\section{Introduction}

In the middle of a growing and very competitive seed industry in the late 1960s to early 1970s in South Africa, South African commercial farmers were faced with many hybrid maize seed varieties to choose from. Whereas some of these hybrid varieties were generally good, some habitually failed to perform optimally in farmer localities. Farmers speculated on which seed to grow and often were unable to select appropriate varieties for their localities. Advertising and informal farmer channels made it even more difficult for farmers to adequately select and procure seed of good character, which regularly led to the planting of sub-standard seed varieties that affected yields. To prevent this, the South African government instituted the National Cultivar Trials (NCTs) for maize in 1976/77, following the enacting of the Plant Improvement Act of 1976 (Act 53 of 1976).

The initial goals and objectives of the trials were and remain threefold. First, the program sought to improve the profitability of commercial maize production by enhancing 
the ability of commercial farmers to identify maize cultivars that are on average highly adapted to farmer localities. Second, the program aimed to curtail the importation and use of poorly adapted maize cultivars in South Africa. Thirdly, the trials sought to ensure that commercial agriculture is systematically improved in South Africa, by safeguarding farmers against the use of maize cultivars that are poorly adapted in maize producing localities. To implement these three objectives, maize cultivar evaluation trials were started and are conducted in over 50 localities covering the key maize producing regions of South Africa. Results are published in user friendly pamphlets which are disseminated to farmers to assist them to identify cultivars which are best suited in their localities. At the farm level, the maize trials provide an unbiased and scientifically grounded service to the maize industry through which correct cultivar selections are made, based on yield potential (and yield probability), quality and stability characteristics under variable soil and climatic conditions. The national maize trials also make it possible for extension agents to recommend maize cultivars which are highly adapted in farmer localities, ending many years of farmer speculation regarding which seed to plant. Typically, farmers adopt the highly ranked maize cultivar(s) in their localities, an activity that places emphasis on the adoption of cultivars that are comparatively more productive in farmer localities. Thirty seven years since the national maize trials were instituted, the economic benefits of the program in South Africa need to be evaluated.

This study hypothesises that the national maize cultivar trials have added meaningful yield benefits to farmers in South Africa and that continued investments into the trials are a prudent use of public funds. Lack of evidence on the economic value of the maize trials in South Africa, however, has led to erroneous assumptions about the trials that imply that farmers were going to intuitively select and plant the correct maize cultivars for their localities even in the absence of the trials. The underlying implicit view of these assumptions is that farmers have full access to all the information required to make informed maize cultivar choices. These assumptions ignore that, in the absence of maize cultivar evaluation trials results, the farmer may be unable to compare the performance efficacy of alternative maize cultivars developed by different seed companies for a specific locality. It also ignores the fact that the alternative (of not having the information from these trials) would be costly in terms of the time and resources spent by the farmer to source these from peers.

Although it is accepted wisdom that the Agricultural Research Council (ARC) has contributed significantly towards improving the productivity of the agricultural sector in South Africa (Thirtle et al., 1998; Liebenberg, 2013), in recent years, funding for the Council has been shrinking in inflation-adjusted terms - a reality that has meant that within ARC 
different research programs have to compete for the available funds. In such a financial situation, the inclination is to shelve programs whose value is unknown or remain obscured. Whilst this is understandable, for example, agR\&D cannot continue without funding, turning research off and on could have serious implications for productivity growth in the sector, especially if the benefits of a program outweigh its costs. Without evidence on the economic value of the national maize trials, the ability of ARC to justify the continued allocation of funds into the programme and to motivate for more funding to broaden the scope and coverage of the trials is limited.

This study quantifies the economic benefits associated with the national maize trials only. The value of crop breeding research (CBR) and other forms of research on maize that have led to growth in maize yields are acknowledged, but are not directly addressed in this study. The next section briefly outlines the nature of the national maize trials to give a context of the research value of the trials. The method of analysis is presented in the third section. The paper concludes with a presentation and discussion of the findings.

\section{The value of the national maize trials}

Seed is one of the most important inputs in agricultural production. Morris (1998: 1) writes that "Of all the inputs used in agriculture, none has the ability to affect productivity as much as seed" whilst Eaton (2013: 3) agrees that "the genetic code of seeds sets the potential frontier of production, in terms of quantity and quality." Any use of other inputs ${ }^{1}$ other than seeds "determine how much of the potential embodied by the seed is realised" (Eaton, 2013: 3). In this sense, seed or cultivar choice becomes the most important decision faced by a grains producer (Pretorius, 1979). Cultivar testing constitutes a major step in facilitating the process of identifying suitable cultivars for different environments (Olver, 1982). In South Africa, the maize trials provide cultivar performance information covering a variety of cultivar characteristics such as length of growing season, the yield potential of a cultivar in a given farmer locality, disease resistance, drying rate, and standing quality (Olver, 1982; Gevers, 1988; 1992; ARC, maize cultivar trials publications). For farmers, these properties are very important when choosing cultivars to ensure that the best-adapted cultivars in a locality are selected (Pretorius, 1979). In this sense, the national maize trials necessitate the continuous adoption of best-adapted maize cultivars in different localities in South Africa (Gevers, 1982). As the trials are conducted every year, they form part of the sustained

\footnotetext{
${ }^{1}$ Including land, capital, labour, fertilisers and pesticides.
} 
research on genotype $\mathrm{x}$ environment $(\mathrm{GxE})$ interactions of different maize varieties in different localities (Gevers, 1988) and therefore lead to what Alston et al. (1998) has termed the 'development of useful knowledge'. This useful knowledge on cultivar performance leads to an increment in the stock of knowledge regarding the performance of alternative maize cultivars which enhances the adoption of highly adapted cultivars as and when they become available to farmers.

As Hall and Khan (2003: 2) observe: "it is diffusion rather than invention or innovation that ultimately determines the pace of ... [yield] growth and the rate of change of productivity. Until many users adopt a new technology, it may contribute little to our wellbeing". Maize cultivars are evaluated every year to generate up-to-date cultivar performance information which assists farmers in identifying suitable cultivars for their respective localities. Extension agents also use this information to recommend suitable cultivars to farmers (Birch, 1982). The program generates benefits for as long as farmers and other economic actors in the maize industry in South Africa use the information. Indeed, as Alston et al. (1998: 29) note "once research leads to an increment in the stock of knowledge or an improvement ... [in the adoption of superior technologies], that increment to knowledge or improvement [in the adoption of superior technologies] yields a stream of ... benefits that continues until the knowledge or technology becomes obsolete".

\section{Quantifying the overall benefits and costs of the national maize trials in South}

\section{Africa}

The literature that analyses the value of agR\&D initiatives goes back to the seminal work of Zvi Griliches (1958) who noted that the analysis of returns to public and private research expenditures should be based on the assumption that they are approximately equal to the value of the resulting increase in output and a price adjustment. Drawing from Griliches (1958), Pardey, Alston, Chang-Kang, Magalhaes, and Vosti (2004) show that to quantify the gross annual research benefits (GARB) attributable to an agR\&D initiative, it is important to isolate the shifts in yield attributable to agR\&D in relation to some base period or year. Pardey et al. (2004) also emphasise the use of adoption rates of - and area planted to the technology under evaluation to estimate the gains in yields attributable to the technology. Since agriculture, especially crop production, is a physically expansive sector (Beddow, 2012; Pardey, Alston, and Chan-Kang, 2012) and different regions have different production potentials, attribution methods emphasise the use of indices to adequately capture the gains attributable to agR\&D. These indices can either be weighted based on area planted, or based 
on national estimates of agricultural production. Once shifts in agricultural production due to agR\&D have been identified, several efficiency measures have been developed to calculate economic benefits and the rate of return of an investment in agR\&D.

\subsection{Yield Benefits of the Maize Trials}

To calculate the benefits of the national maize trials, this study uses the attribution methods developed by Pardey et al. (2004). The study focused only on yield benefits. Nonyield benefits such as grain quality, improved fodder quality and shorter growth cycle are complex to isolate (Morris, 2002) and are left out of the analysis as will be shown.

To estimate the contribution of the maize trials to improvements in maize yields the study calculated the gross annual research benefits (GARB) attributable to the maize trials. These were assumed to be equivalent to a proportion of the value of additional output attributable to crop breeding research $(\mathrm{CBR})$, measured by the product of the value of production $(P Q)$ and the proportional gain in yield $(k)$ associated with the adoption of the information provided by the maize trials. Given that it proved difficult to isolate and value the contribution of seed choice to maize yields, we followed the procedure of Morris (2002) that estimates economic benefits generated by an agR\&D initiative under a range of plausible yield gain estimates $(\alpha)$ was used. Such that:

$$
G A R B=\alpha k P Q
$$

where $\alpha$ represents a fraction of the credit that will go to the national maize trials and is assumed to range between $5 \%$ and $15 \%$ of total yield benefits. In so doing, these percentages assist in attaching a monetary value to the benefits generated by the trials and provide useful insights in answering the question of whether or not the use of public funds to evaluate maize cultivars has provided any benefits to maize farmers and South Africa.

Drawing from Pardey et al. (2004), an evaluation of the additional gain (or loss) in yields $\left(k_{l t}\right)$ due to the national maize trials was accomplished through:

$$
k_{c l t}=\left(\frac{Y_{c l t}^{a}-Y_{c l t}^{b}}{Y_{c l t}^{a}}\right)
$$

where $Y_{l}^{b}$ is an index of experimental yields at locality $l$ at time $t$ before the institution of the national maize cultivar trials (and $Y_{l}^{b}=\sum_{i=1}^{n} Y_{i l} \pi_{i l b c}$, where $\pi_{i l b c}$ denotes the portion of total area planted to the maize crop $(c)$, sown to a maize cultivar $i$ in locality $l$ chosen without the maize trials in the base year $b), Y_{l t}^{a}$ denotes an index of experimental yields after the institution of the maize trials at time $t$. 
To quantify the total benefits, $B_{l t}$, attributable to the maize trials at locality $l$ in year $t$, the k-shift is used as follows:

$$
B_{l t}=\alpha k_{l t} P_{t} Q_{l t}
$$

where $P, Q$ and $\alpha$ are as defined in equation 1 .

The study used experimental yields to quantify the additional gain in maize yield, $k_{l t}$. Experimental yields are used because "many of the variables that influence yields are deliberately held constant, a practice that helps to isolate the effect[s] of the ... [adopted cultivars] "(Pardey et al., 2004). As experimental yields tend to be significantly higher than commercial yields the experimental yields were transformed into commercial yields using the following equation:

$$
\widehat{Y}_{l t}=\frac{Y_{f t}}{\sum_{i=1}^{n=4} Y_{e t}}
$$

where $\hat{Y}_{l t}$ represents a factor of experimental yields $\left(Y_{e t}\right)$ at locality $l$ at time $t$ to commercial yields $\left(Y_{f t}\right)$ at time $t$. Rewriting equation (3) using the actual $(a)$ and the base $(b)$ values and the factor of experimental yields to commercial yields produces:

$$
\widehat{k}_{l t}=\left(\frac{\widehat{Y}_{l t}^{a}-\widehat{Y}_{l}^{b}}{\hat{Y}_{l}^{a}}\right)
$$

The estimate of $\hat{k}$ in equation (5) can also be used to quantify the proportional decrease in maize production had the national cultivar trials not been instituted (or in the counterfactual scenario) given the actual scenario of improved production due to increased rate of adoption of high yielding cultivars as a result of the maize trials, ceteris paribus.

Indeed, by simply multiplying the proportional decrease in production by the actual value of production gives a value of production forgone (Pardey et al., 2004) had farmers continued to speculate about which seed to procure and plant. Given equation 5, the total economic benefits attributable to the national maize trials in locality $l$ in year $t$ were specified as follows:

$$
\begin{aligned}
& B_{l t}=\alpha \hat{k}_{l t} P_{t} Q_{l t} \\
& B_{l}=\sum\left(\alpha \hat{k}_{l t} P_{t} Q_{l t}\right)
\end{aligned}
$$

Equation 6 gives an estimate of the total economic benefits attributable to the national maize trials. However, to get the total value of economic total value of benefits attributable to the maize trials, we used equation 6 , which sums all the benefits at time $t$. These economic benefits come at a cost, which we turn to next. 


\subsection{Costs of the NCTs}

The cost of the activities involved in the conduct of the cultivar evaluation trails during the study period was estimated using a number of procedures. In the following sections these are discussed and motivated.

\subsubsection{Labour costs}

Labour costs are by far the main costs incurred when conducting the trials. The labour requirements of the national maize trials are activity-specific: there are researchers, technicians and support staff. Through a record of all staff involved in the trials (Department of Agriculture, 1984; Prinsloo, 2013 (Pers. Comm)) we established the number of personnel, at different levels of qualifications (e.g. Ph.D., MSc., BSc. and other qualifications for support staff). An estimate of the amount of time that each employee spends on the trials a year was used to quantify the portion of labour costs for the trials. For agronomists, the proportion of time spent on the trials was 10 percent whilst for other support staff such as field workers, it ranged between 60 and 80 percent of their time in the trials.

The share of labour costs dedicated to the national maize trials $\left(S N C_{c l}\right)$ was estimated using ARC salary data as follows:

$$
S N C_{c l}=\frac{\sum_{q} W_{q c l t} S_{q c l} L_{q c l t}}{\sum_{q} W_{q c l t} L_{q c l t}}
$$

where $W_{q c l t}$ denotes qualification class, $q$, for the maize crop, $c$, in each year of the trials, $t$; $S_{q c l t}$ is an estimate of the fraction of time that each respective labour class assigned to the execution of a particular activity in the trials spends in the program at time $t$. Using a time series of total labour costs for ARC's Grain Crops Institute, the share of labour costs associated with the maize trials, $S N C_{c l}$, within ARC were quantified.

\subsubsection{Operational costs}

Operational costs are the costs of activities conducted in the trials excluding labour and capital costs. They include the costs of inputs (such as fertilisers), chemicals (field and laboratory), energy costs (electricity and fuel) and other kinds of supplies necessary to carryout the various activities of the maize trials. A time series of operational costs was developed using data from the ARC-GCI (1993 - 2012) and other forms of data mined from various sources (RSA, 1977 - 1994; Department of Agriculture, 1984). These data were converted into 2012 currency values by use of the consumer price index (CPI: $2012=100)$. This 
allowed the study to generate an estimate of the operational costs related directly to the national cultivar trials, for each of the years considered in this study.

\subsubsection{Capital costs}

To conduct the maize trials, ARC needs various classes of capital which include land, machinery and equipment, buildings and other forms of physical capital. Drawing from Pardey et al. (2004) the total value of capital directly employed in carrying out the various activities of the maize trials is computed based on the corresponding shares of labour together with the operational costs for the maize trials. The value of capital stock used for the maize trials for each year is quantified as follows:

$$
S_{c l}=\sum_{k}\left(l-d_{k}\right) S_{k c l(t-1)}+\sum_{k} I_{k c l}
$$

where $S_{k c l}$ is the stock of capital and $I_{k c l}$ denotes the capital investment in capital of class $k$ for the maize trials, $c$, at time $t$; $d_{k}$ is the annual rate of capital depreciation ${ }^{2}$ (capital of class $k$ ). To calculate the opportunity cost of foregone earnings from resources tied up to durable assets that are used for the maize trials, a geometrically declining depreciation profile is used, such that:

$$
U C_{c t}=\sum_{k} S_{k c l}\left(d_{k}+r_{k}\right)
$$

where $U C_{c l}$ is the user cost of capital for the maize trials $c$ at time $t$, and $r_{k}$ is the discount rate. Drawing from Alston et al. (1995) and Pardey et al. (2004), a risk-free discount rate is used.

To calculate labour costs, a time series of salary data by qualification was developed using different data sources. From 1977 to 1993, a time series of staff salary data was estimated using salary data for the different classes of labour (which were developed through an elaborate inventory of staff involved in the trials, using the insights of long serving staff members in ARC-GCI in Potchefstroom) involved in the trials. From 1994 to 2012, ARC provided data on staff remuneration based on qualification class. Using real staff time-log data and an estimate (in cases where there was no data, which generally refers to the period before the formation of $\mathrm{ARC}$ ) of the share of time, in fulltime equivalents, which each qualification class spends on the national maize trials the cost of labour for the trials was estimated.

\footnotetext{
${ }^{2}$ Pardey et al. (2004: 33) used an annual depreciation rate of 0 percent for land, 3 percent for buildings, 4 percent for the discount rate of foregone income and 10 percent for other investments. Considering that the South African economy is similar to that of Brazil, for example, both South Africa and Brazil are in the same economic Bloc, this study uses the same percentages for land and buildings. For the discount rate of foregone income, the study uses 8 percent, whilst 10 percent is used as the reinvestment rate.
} 
To estimate the labour costs for headquarters, the labour costs were inflated by a percentage which was calculated first by conducting an inventory of all the projects that the ARC-GCI was involved in since 1992 (when ARC was formed). This was followed by quantifying the proportion of the expenditures of the national maize trials given the total research expenditures of the GCI. This gave varying percentages, based on year, which were then used to account for the labour costs of headquarters attributable to the national maize trials.

\subsection{Costs incurred by collaborators}

It is important to note that labour costs and any other costs incurred by co-operators (mainly private seed companies) who participate in the trials are not available. Although seed companies pay a fee to have their cultivars evaluated in the national maize trials, they still incur labour costs and other research expenditures when conducting the trials, which have to be included to quantify the true economic value of the national maize trials. Whilst costs do not change the yield gains attributable to the maize trials they do have an effect on the results of the efficiency measures such as the benefit-cost ratio which may be overstated if the research costs incurred by seed companies are left out.

To avoid overstating the economic value of the national maize trials, we assume that the labour costs and research expenditures incurred by seed companies in any locality were equivalent to $50 \%$ of the costs incurred by ARC in that locality. The motivation for the use of

$50 \%$ is that the expenditures of the ARC in the maize trials are mainly for expertise and expenditures such as fuel, inputs, and miscellaneous costs. For the purpose of the trials in a specific locality this can either be shared or be incurred by one agency. For example, once expenditures related to land preparation, fertilisation and all other inputs in the trials have been incurred they can't be accounted for twice. Thus, once the ARC has prepared the land, the collaborator cannot incur costs for land preparation, it can only share in the costs incurred by ARC and vice versa. For costs such as expertise, labour, fuel, accommodation and other costs that are incurred by ARC's collaborators in the trials, ARC's costs of research per locality per year in those localities where ARC shared responsibilities with co-operators were inflated by $50 \%$. This produced a series of costs which was generally $50 \%$ higher than the initial series without the research costs incurred by the private seed companies and collaborators in the trials. 


\subsection{Adoption rates}

Data on the adoption rates of individual maize varieties in the agricultural sector of South Africa are very scarce. However, estimations by Laubscher (1970), Grobbelaar (1980) and Gevers (1988) reveal that the sale of hybrid seed struggled to gain traction in South Africa from the first year of introduction in $1949^{3}$ to the late $1960 \mathrm{~s}$. The area planted to hybrids only reached $70 \%$ in 1970 after 21 years since the first successful hybrid, the Kansas line K64, was introduced (Laubscher, 1970; Gevers, 1988). Figure 1 presents average rates of adoption of maize varieties in South Africa, from 1950 to 2012. Adoption rates of hybrid varieties of maize reached 90 percent in 1985 (Gevers, 1988), as shown on Figure 1.

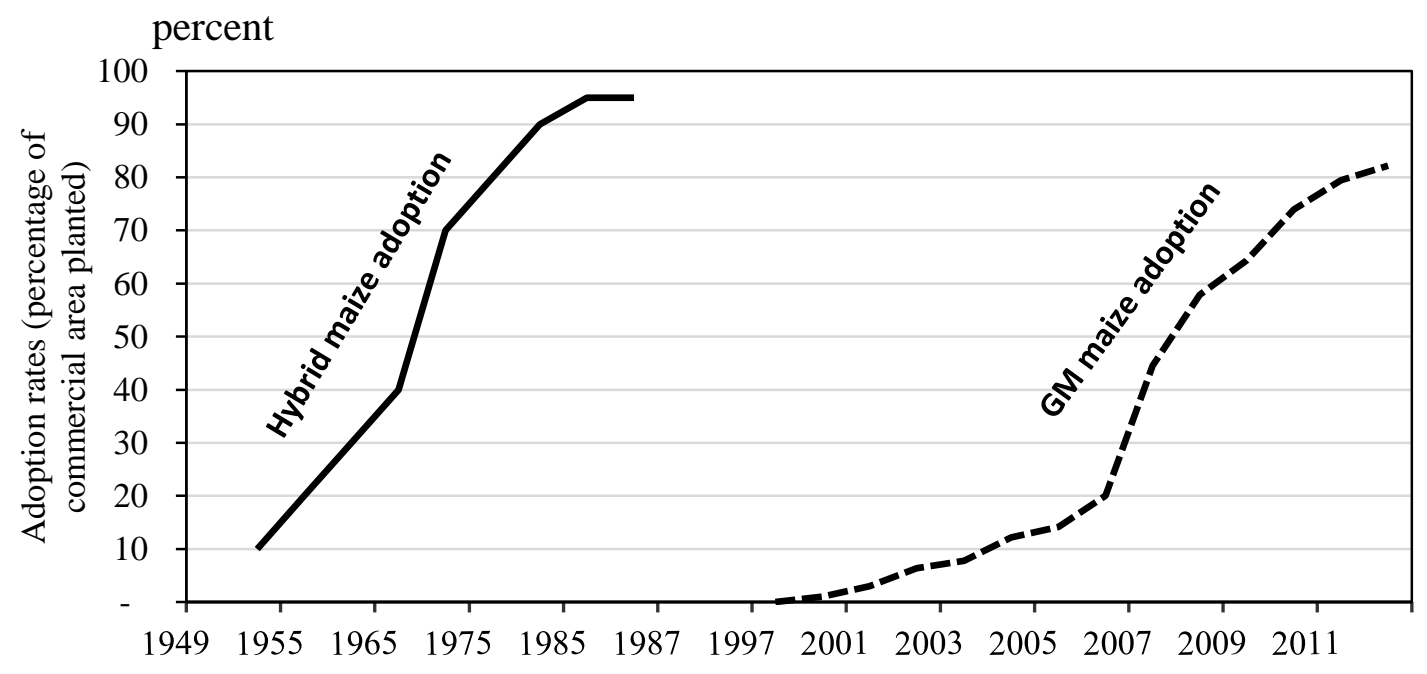

Figure 1 Adoption rates of improved maize seed in South Africa.

Source: $\quad$ Authors' own calculations using data from Laubscher (1970), Grobbelaar (1980), Gevers (1988) and Gouse (2013, Personal Communication).

Note: $\quad$ The adoption rates are for commercial maize producers only.

Genetically modified (GM) maize varieties were introduced in South Africa in 1997 following the passing of the Genetically Modified Organisms Act of 1997. Unlike hybrid seed which took 21 years to reach adoption rates of $70 \%$ or 25 years to reach $90 \%$ of area planted (Gevers, 1988), it took about 10 years for GM varieties to reach $70 \%$ of area planted (Gouse, 2013, personal communication), as shown by the dotted line on Figure 1. In 2012, the area planted to GM maize varieties reached $80 \%$.

\subsection{Matching Benefits and Costs}

To match the streams of research benefits and costs, the study compares the benefits and costs by aggregating the flows over time (Pardey et al., 2004; Alston et al., 1998).

\footnotetext{
${ }^{3}$ The first 1.3t of hybrid seed were sold to South African commercial maize farmers in 1949 (Grobbelaar, 1980: 4).
} 
Several methods that aggregate research flows over time have been proposed. Alston et al. (1998) recommend the use of efficiency measures such as the net present value (NPV), benefit-cost ratios (BCR) and the internal rate of return (IRR). Recently, Pardey et al. (2006), Alston et al. (2011) and Rao et al. (2013) have also proposed the use of a modified internal rate of return (MIRR), by showing the inefficiencies of the IRR. These efficiency measures address the time value of an investment. For the purpose of this study, the NPV, BCR and MIRR are used to match the streams of benefits and costs of the maize trials. A risk free discount rate of 8 percent ${ }^{4}$ is used for the NPV whilst 8 and 10 percent is used for the MIRR.

\subsection{Data}

The study used data from a large dataset compiled from national maize trial reports published by the Department of Agricultural Technical Services (DATS) from 1977 to 1992 and ARC from 1993 to 2012 in South Africa. The Highveld region ${ }^{5}$ of South Africa was used because during the course of the last 25 years, it accounted for over $89 \%$ of the area planted to maize. The reports present yield in tons per hectare for an average of 50 genotypes for 55 localities a year. The trials evaluate the adaptability of commercial genotypes to a wide range of yield potentials. The results are indicative of genotype performance under specific environmental conditions occurring during a season. Genotypes are ranked according to their performance on a wide range of environmental and agronomic factors. Grain yield is the only parameter that is statistically analysed in the trials which allowed the study to evaluate the effects of the top four ranked cultivars in the trials on yield growth given the counterfactual scenario of no national maize trials. The additive mean effects and multiplicative interaction (AMMI) analysis is used to indicate the adaptability and stability of genotypes for different environments. Statistical procedures are used to identify and exclude outlier trials from the AMMI model. The AMMI model analysis is then used to rank and further select the best four genotypes in a locality. The information is disseminated to commercial farmers, through extension agents and other means. Typically, farmers are understood to select a genotype or genotypes from the best four genotypes in a locality. The top four cultivars selected using the AMMI model's best four cultivars vary from one locality to the next and represent only a small fraction of the total cultivars tested in a given locality.

\footnotetext{
${ }^{4}$ This is given that in 2012 the South African Government's 10 year Treasury bond was $~ 8 \%$ (National Treasury, 2012).

${ }^{5}$ The Highveld region covers three provinces, namely the Free State, Mpumalanga and North West Provinces. In terms of key farming towns, the Highveld region covers the towns of Lichtenburg, Bethal, Ladybrand and Bultfontein.
} 
Costs data was compiled from different publications of the then Department of Agricultural Technical Services and from 1994; data was obtained from ARC's financial databases.

\section{Empirical Analysis and Results}

\subsection{Yield Benefits}

Using the dataset of all commercial genotypes evaluated in the trials, an estimate of the average experimental yield of commercial cultivars in a locality was calculated for all the localities covered by the national maize trials. Commercial maize yields per year are reported by various sources in South Africa. To better capture improvements in yield an index of experimental and commercial yields was developed. As illustrated, experimental yields grew at a higher rate than commercial yields (Figure 2). This can be attributed to a lower base year value for commercial yields probably due to lower yields realised by farmers in 1977 . In some years, yield growth fluctuates between higher gains and low gains which are attributable to cultivar plantings coinciding with a difficult production season in the Highveld region.

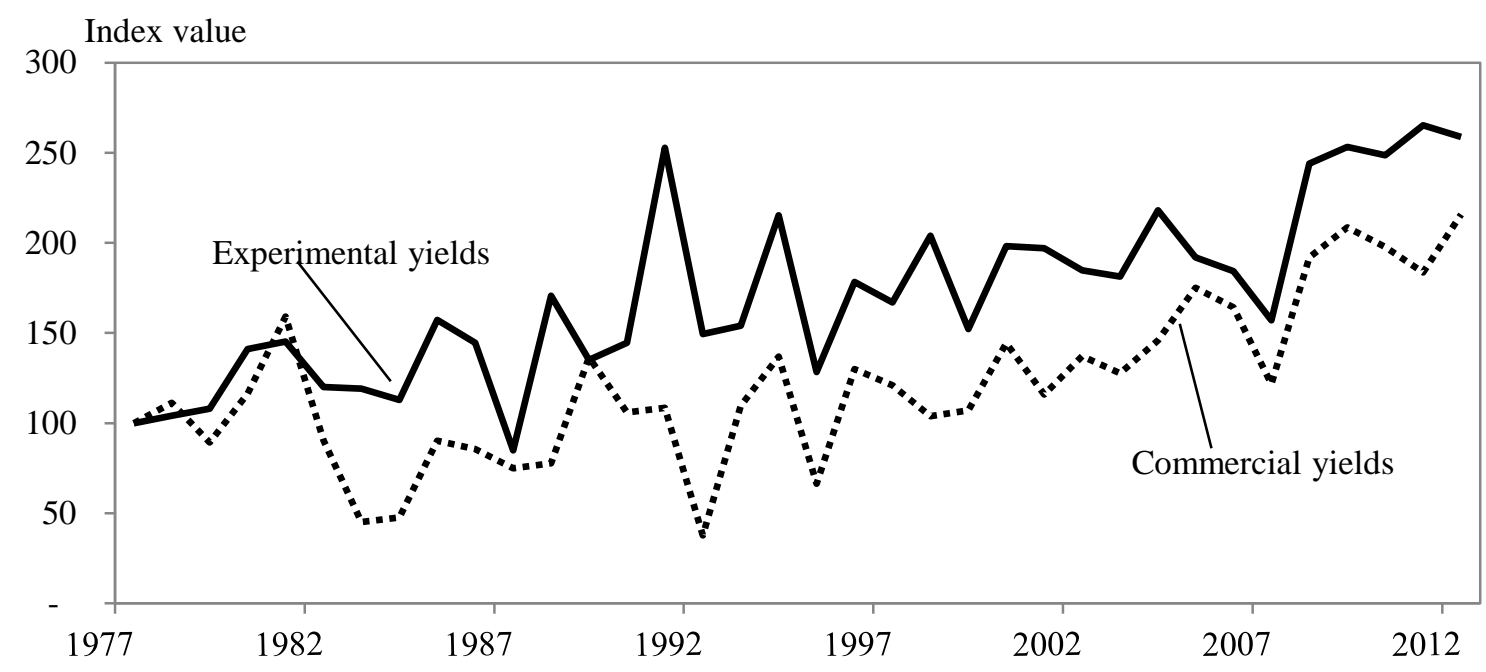

Figure 2 Index of maize varietal improvement in relation to commercial yields.

Source: Authors' own calculations, using data from the GCI (1977-1992); ARC-GCI $(1993-2012)$.

Figure 3 shows the weighted average commercial, experimental yields and the weighted average experimental yields of the AMMI model's best four genotypes in a trial locality. Note that the average experimental yields of the AMMI model's best four cultivars are generally higher than the weighted average experimental yields for all the 50 genotypes in a locality. This is attributed to choosing a cultivar or cultivars from the top four ranked 
cultivars in a locality, as opposed to selecting a cultivar from all the 50 genotypes in a locality with no performance information.

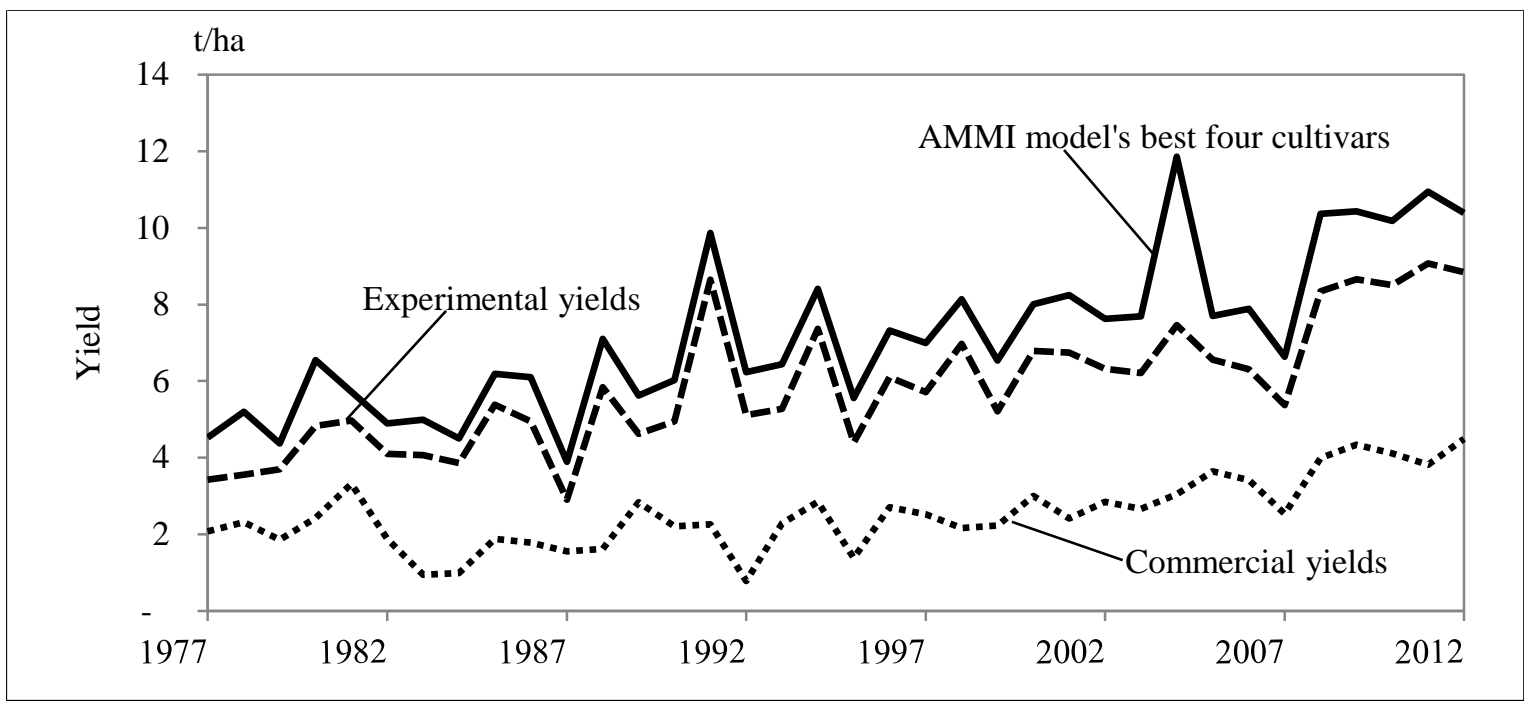

Figure 3 Weighted average experimental yield vs. weighted average commercial yield of maize in the Highveld region.

Source: $\quad$ Authors' own calculations based on unpublished data from the ARC-GCI.

Using equation 5, the yield gains attributable to the national maize cultivar trials were quantified. Figure 4 provides a detailed look at the yield gain estimates attributable to the national maize trials. On the graph, the k-shift values are for the 5 percent level of assumed plausible yield gain estimate attributable to the NCTs for maize. The k-shift values fluctuate, although they remained, for the most part, positive. Where the k-shift values show a decline in yield gains, the decline may have come about because of cultivar plantings coinciding with bad production years. The fluctuations can further be attributable to unfavourable weather conditions during planting or crop growth stage.

(Proportional shifts in supply, $k$ )

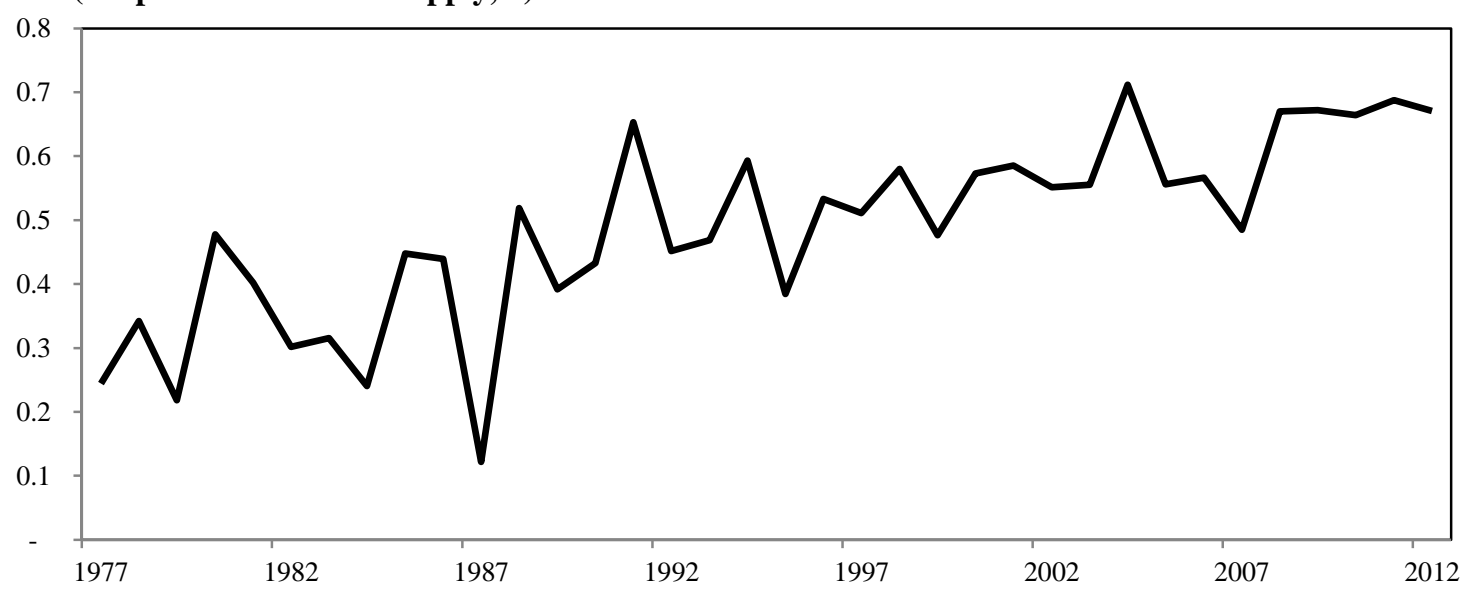

Figure 4 Proportional shifts in maize supply $(k)$ for the Highveld region. 
Source: Authors' own calculations.

Note: $\quad$ K-shift values were calculated using equation (5).

\subsection{Yield gain estimates}

Table 1 illustrates the yield gain benefits attributable to the national maize trials at the 5 to 15 percent plausible yield gain estimates attributable to the maize trials. The yield benefits range from $24.3 \mathrm{Kg}$ per hectare per year at the 5 percent level of plausible yield gain estimate attributable to the national maize trials to $72.9 \mathrm{Kg}$ of output per hectare per year at the15 percent level of the assumed plausible yield gain estimates attributable to the maize trials in the Highveld region. These increases in output per hectare also represent the output that farmers could have lost had the program not been started. The estimates show that as the assumed plausible yield gain estimates attributable to the maize trials increases, so do the estimates of yield gains in $\mathrm{Kg} / \mathrm{ha}$.

Table 1 Overview of Yield Gains Attributable to the national maize cultivar trials

\begin{tabular}{llrrrrr}
\hline \multirow{2}{*}{$\begin{array}{l}\text { Years } \\
\text { Crop }\end{array}$} & \multicolumn{5}{c}{$\begin{array}{c}\text { Additional yield gain due to the selection of good cultivars if } \\
\text { NCTs contributed }(\partial)(\mathrm{kg} / \mathrm{ha})\end{array}$} \\
\cline { 2 - 6 } & of trials & $5 \%$ & $7.5 \%$ & $10 \%$ & $12.5 \%$ & $15 \%$ \\
\hline \multirow{3}{*}{ Maize } & $1977-2012$ & 24.3 & 36.4 & 48.6 & 60.8 & 72.9 \\
\hline \hline
\end{tabular}

Source: Authors' calculations.

Overall, the results show that continued investments into the evaluation of alternative maize cultivars in the various localities of the Highveld region in South Africa has produced noticeable yield benefits for commercial maize producers. Whether one can expect the same results if the analysis were done for smallholders depends on a host of factor, among which the skills and the resources available to the smallholder in combination with their current yields achieved. If the use of more suitable cultivars would results in proportionally greater yield benefits one would expect them to experience even better results, however, this is a matter that one can only postulate about in the absence of detailed information on their situation.

\subsection{Value of economic benefits}

To quantify the total value of economic benefits attributable to the national maize trials, the study used equation 6. The present value, net present value (NPV) and the benefit 
cost ratio of economic benefits were used as efficiency measures for the program. To calculate the rate of return to the investments made in the national maize trials, the modified internal rate of return was used. Table 2 presents summary estimates for the present value and net present value of the total economic benefits of the national maize trials. Also shown in Table 2 are the benefit-cost ratios and MIRR of the investments made into the national maize trials. These estimates represent the present value and net present value of the benefits that have accrued to farmers as a result of being able to select maize cultivars that are better adapted to their localities.

Table 2 Estimated value of economic benefits attributable to the national maize trials in South Africa

\begin{tabular}{|c|c|c|c|c|c|}
\hline \multirow{2}{*}{$\begin{array}{l}\text { Efficiency } \\
\text { measure }\end{array}$} & \multicolumn{5}{|c|}{ Total benefits if maize trials contributed } \\
\hline & $5.0 \%$ & $7.5 \%$ & $\mathbf{1 0 . 0 \%}$ & $12.5 \%$ & $15.0 \%$ \\
\hline \multirow{3}{*}{$\begin{array}{l}\text { Present value } \\
\text { Net present } \\
\text { value }\end{array}$} & \multicolumn{5}{|c|}{ (thousands, 2012 rands) } \\
\hline & $1,400,662$ & $2,100,994$ & $2,801,325$ & $3,501,656$ & $4,201,987$ \\
\hline & 108,434 & 164,154 & 219,873 & 275,593 & 331,312 \\
\hline \multicolumn{6}{|c|}{ (Benefits that accrued to South Africa for every rand spent on the national maize trials, 2012 rands) } \\
\hline BCR & 37.1 & 55.6 & 74.2 & 92.7 & 111.3 \\
\hline MIRR & $20 \%$ & & & & \\
\hline
\end{tabular}

Source: Authors' calculations.

Since the yield benefits attributable to the NCTs, $\alpha$, are estimated between a lower bound of 5 percent and an upper bound of 15 percent, Table 2 also shows the estimated economic value of the benefits attributable to the national maize in the different levels of plausible yield gain estimates attributable to the national maize trials. Keeping in mind that the national maize trials are funded by both the State and the Maize Trust and that seed companies also incur costs for the trials, the estimated economic benefits are therefore shared between the ARC, the co-operators and the Maize Trust. No attempt was made to attribute the benefits to the different role players. The economic value represents the total benefits of the maize trials to South Africa.

The estimated present value of financial benefits that accrued to South Africa through investments made by the ARC and the Maize Trust into the national maize cultivar trials is R1.4 billion at the 5\% level and R4.2 billion at the $15 \%$ level. This represented between 4 and 11 percent of the total gross value of maize production in 2012. The results show that the 
estimated NPV for the investments made into the national maize cultivar trials is R108.4 million at the 5\% level and R331.3 million at the $15 \%$ level.

The value of the benefits that have accrued to the South African economy from every rand invested by the ARC (including its co-operators) and the Maize Trust into the national maize trials is calculated using the benefit-cost $(\mathrm{BC})$ ratios. The $\mathrm{BC}$ ratios represent the income that the program has generated in South Africa in rand terms for every rand invested by the ARC. In broad terms, the ARC has generated a value of R37.1 for every rand spent in the national maize trials at the 5\% level rising to R111.3 at the assumed plausible yield gain estimate attributable to the national maize trials of $15 \%$.

In order to assess the rate of return of the investments made into the national maize trials, the study uses the modified internal rate of return (MIRR). Using a discount rate of 8 and 10 percent, the estimated MIRR for the national maize cultivar trials is 20 percent, suggesting that the national cultivar trials have had a fairly good rate of return. Broadly, the results confirm that past investments into the national cultivar trials by the Summer Grain Crops Research Institute, and beginning from 1992 the ARC-GCI, have been a wise use of public funds.

\subsection{Sensitivity Analysis}

In their study titled: 'Assessing and Attributing the Benefits from Varietal Improvement Research in Brazil', Pardey et al. (2004: 66) observe that because there has been a tendency to overestimate rates of return for such studies, due diligence needs to be paid to "aspects of the analysis involving analytical judgements that have repercussions on the results". A key consideration is the choice discount rate. According to Pardey et al. (2004: 68) "the appropriate interest rate for discounting streams of research costs and benefits is the social opportunity cost of public funds committed to long-term investments." They note that in developing economies a higher interest rate could be more justifiable given the high costs of capital.

In that spirit, this section tests the effect of selecting a different discount rate on the magnitude of the benefits of the national maize trials. The net present value of benefits, the benefit-cost ratios and the MIRR for the maize trials are re-estimated using two discount rates (5 and 14 percent). The study also used 5 and 14 percent as corresponding discount rates for the MIRR. To test the sensitivity of the estimated benefit-cost ratios and the MIRR to costs, costs were inflated by 25 percent. 
The resultant net present value of benefits, the benefit-cost ratios and the MIRR are reported on Table 3. As expected the benefit-cost ratios shown are sensitive to changes in costs and discount rates. However, the $\mathrm{BC}$ ratios are not sensitive to changes in the discount rates. The $\mathrm{BC}$ ratio decreased by between R7.4 at the 5 percent level and R22.3 at the 15 percent level. This suggests that there have been greater yield gains in the latter years of the trials, than in the early days, which is generally attributable to an increase in the adoption of GM maize cultivars which reached $80 \%$ in 2012 and imbued many benefits to farmers.

Table 3 Sensitivity analysis

\begin{tabular}{|c|c|c|c|c|c|}
\hline \multirow{2}{*}{$\begin{array}{l}\text { Efficiency } \\
\text { Measure }\end{array}$} & \multicolumn{5}{|c|}{ Total benefits if NCTs contributed } \\
\hline & $5 \%$ & $7.5 \%$ & $10 \%$ & $12.5 \%$ & $15 \%$ \\
\hline & \multicolumn{5}{|c|}{ (thousands, 2012 rands) } \\
\hline NPV (If $r=5 \%$ ) & 245,283 & 372,203 & 499,124 & 626,044 & 752,964 \\
\hline NPV (If $r=14 \%$ ) & 48,145 & 73,057 & 97,969 & 122,881 & 147,794 \\
\hline BCR & 29.7 & 44.5 & 59.3 & 74.2 & 89.0 \\
\hline MIRR & $\begin{array}{r}r=\mathbf{5 \%} \\
18 \%\end{array}$ & $\begin{array}{c}=14 \% \\
23 \%\end{array}$ & & & \\
\hline
\end{tabular}

Source: Authors' own calculations

Note: Costs were inflated by $25 \%$.

Table 3 further illustrates that the net present value of benefits and the MIRR are sensitive to changes in the discount rates. Using a discount rate of 5 percent increases the NPVs of the national maize trials, whereas increasing the discount rate to 14 percent decreases the NPVs. The estimated net present values of benefits obtained using a discount rate of 5 increased substantially than when a discount rate of 8 percent is used. When the discount rate is 5 percent, the MIRR decreased to 18 percent, suggesting that the benefits are sensitive to the discount rate used and an increase in costs. For the kind of analysis that this study was interested in, the MIRR is used for comparison purposes to the benefit cost ratios which are good enough in giving direction on the value of the national cultivar trials in South Africa.

\section{Conclusions}

The objective of this study was to quantify the extent to which the national maize trials have contributed to growth in maize yields in South Africa, and to conduct a benefitcost analysis of the investments made by ARC into the programme. The study employed robust methods which have been used in attribution studies elsewhere (see for example 
Pardey et al. (2004); Stander (2012)) modified to suit the focus of the national cultivar trials in South Africa. Because it proved problematic to isolate the contribution of seed choice to yields, other ways of conducting the analysis were considered. Yield gain estimates were instead used to quantify the contribution of seed choice to yield growth. This method involved specifying different levels of plausible yield gain estimates attributable to seed choice and thereafter quantifying benefits. The interpretation of results focused on the lower bound ( 5 per cent level) of the assumed plausible yield gain estimates. Given the varied performance of alternative maize cultivars and the spatial variability in environmental and climatic conditions in the various maize producing localities of South Africa, this study provides evidence that the continued evaluation of maize cultivars in these environments is indispensable to farmers and that the program should be continued.

Of immediate importance to ARC would be to expand the coverage of the trials into the smallholder farming sector where maize cultivar trials are not being conducted, which will require additional funding. Forward looking (ex ante) studies that will estimate the benefits of introducing maize cultivar trials in smallholder farmer localities will help in developing an idea of how much funding will be required and to provide estimates of the resultant benefits that will likely accrue to smallholder farmers and to South Africa.

\section{Acknowledgements}

The authors would like to thank Ms Petro Fourie and Dr Merinda Visser of GrainSA for their help with farmer surveys. The views of this paper are those of the authors.

\section{References}

Alston, JM., Andersen, MA., James, JS., and Pardey, PG. (2011). "The Economic Returns to U.S. Public Agricultural Research.” American Journal of Agricultural Economics 93(5): 1257-1277.

Alston, JM., Pardey, PG., and Roseboom, J. (1998). Science Under Scarcity: Principles and Practices for Agricultural Research Evaluation and Priority Setting. CAB International.

Beddow, JM. (2012). A Bio-economic assessment of the spatial dynamics of U.S. Corn production and yields. Unpublished PhD dissertation. St. Paul: Department of Applied Economics, University of Minnesota.

Birch, E.B. (1982). C.1 Guidelines for choosing sunflower cultivars. Department of Agricultural technical Services. Transvaal Region.

Birch, E.B., and Römer, A.A. (1972). Maize in the Eastern Cape. Dohne Agricultural Research Institute, Department of Agricultural Technical Services Technical Communication N109/BIR. Central Library, Pretoria.

Department van Landbou (1984). Verslag van die komitee van ondersoek na die bediening van van die landbou in die republiek van Suid-Afrika. Slegs vir interne en vertoulike gebruik deur die department landbou. Pretoria. 
Eaton, JFD. (2013). Intellectual Property rights, international trade and breeding. Unpublished PhD dissertation. Wageningen School of Social Sciences. Wageningen University.

Geevers, H.O (1982). Evaluation of Improved maize populations. In JG Du Plessis (eds). Proceedings of the Fifth South African Maize Breeding Symposium 1982. Summer Grain Centre, Grains Crops Research Institute. Potchefstroom. Department of Agriculture and Water Supply Technical Communication No. 182: $11-14$.

Gevers, H.O. (1988). Highlights of maize breeding in South Africa. In J.G. Du Plessis (eds.) 'Department of Agriculture and Water Supply Technical Communication: Proceedings of the Eighth South African Maize Breeding Symposium 1988'. Summer Grain Centre, Grains Crops Research Institute. Potchefstroom.

Gevers, H.O. (1992). Progress in maize population improvement. In HO Gevers (eds). Proceedings of the NinthSouth African Maize Breeding Symposium 1990. Summer Grain Centre, Grains Crops Research Institute. Potchefstroom. Department of Agricultural Development Technical Communication No. 232: 15 - 117.

Gouse, M. (2013). Adoption rates of GMOs in South Africa. Department of Agricultural Economics, Extension and Rural Development. University of Pretoria. Pretoria. Personal Communication. 07/11/2013.

Griliches, Z. (1958). Research Costs and Social Returns: Hybrid Corn and Related Innovations. Journal of Political Economy 66(5): 419-431.

Grobbelaar, WP. (1980). Challenges in raising South African maize yields. In H.O. Gevers and J.G. Du Plessis (eds.) Proceedings of the Fourth South African Maize Breeding Symposium 1980'. Summer Grain Centre, Grains Crops Research Institute. Potchefstroom. Department of Agriculture and Water Supply Technical Communication No. 172: 4-9.

Immelman, DW. (1980). Opening address. In H.O. Gevers and J.G. Du Plessis (eds.) Proceedings of the Fourth South African Maize Breeding Symposium 1980'. Summer Grain Centre, Grains Crops Research Institute. Potchefstroom. Department of Agriculture and Water Supply Technical Communication No. 172: 2-3.

Laubscher, FX. (1966). Enriching our hereditary maize plasma. Maize News 1, 5 -7. Maize Board. Pretoria.

Laubscher, FX. (1970). What have we achieved in maize breeding? Maize News 7, 1-8. Maize Board, Pretoria.

Liebenberg, F. (2013). South African Agricultural Production, Productivity and Research Performance in the 20th Century. Unpublished PhD Thesis. Department of Agricultural Economics, Extension and Rural Development. Faculty of Natural and Agricultural Sciences. University of Pretoria. Pretoria.

Louw, JH. (1980). Implications of genotype x environment interactions. In H.O. Gevers and J.G. Du Plessis (eds.) Proceedings of the Fourth South African Maize Breeding Symposium 1980'. Summer Grain Centre, Grains Crops Research Institute. Potchefstroom. Department of Agriculture and Water Supply Technical Communication No. 172: 1314.

Morris, LM. (1998). Maize in the developing world: waiting for a green revolution. In LM Morris (eds): Maize seed industries in developing countries. Lynne

Reinner Publishers, Inc. CIMMYT: I - 12.

Morris, LM. (2002). Impacts of international maize breeding research in developing countries, 1966 98. Economics Program. Mexico DF. (CIMMYT). 64 pages.

Olver, RC. (1982). Cultivar trial procedures and interpretation of results. In J.G. Du Plessis (eds.) Proceedings of the Fifth South African Maize Breeding Symposium 1982'. Summer Grain Centre, Grains Crops Research Institute. Potchefstroom. Department of Agriculture and Water Supply Technical Communication No. 182: 25 - 29.

Pardey, PG., Alston, J.M., Chang-Kang, C., Magalhaes, E.C., and Vosti, S.A. (2004). Assessing and attributing the benefits from varietal improvement in Brazil. Washington, DC: International Food Policy Research Institute. 
Pardey, PG., Alston, JM., and Chan-Kang, C. (2012). Agricultural production, productivity and R\&D over the past half century: an emerging new world order. College of Food, Agricultural and Natural Resource Sciences. University of Minnesota.

Pretorius, JP. (1979). Guidelines for choosing a maize cultivar. Summer Grain Centre. Department of Agricultural Technical Services, Pretoria.

Prinsloo, T. (2013). Department Manager: Crop production. Grain Crops Institute. Agricultural Research Council. Potchefstroom. Personal Communication.

Rao, X., Hurley, TM., and Pardey, PG. (2012). Recalibrating the Reported Rates of Return to Food and Agricultural R\&D. Staff Paper Series P12-8. College of Food, Agricultural and Natural Resource Sciences. University of Minnesota. http://ageconsearch.umn.edu/bitstream/135018/2/RaoEtA12012_v2.pdf

National Treasury (2012). Debt Management Report (2012). Pretoria. Republic of South Africa.

Olver, RC. (1982). Cultivar trial procedures and interpretation of results. In JG. Du Plessis (eds.) Proceedings of the Fifth South African Maize Breeding Symposium 1982. Summer Grain Centre, Grain Crops Research Institute. Department of Agriculture Technical Communication No. 182: $27-29$.

SGC (Summer Grain Centre). (1977 - 1992). National cultivar trials: maize. Department of Agriculture. Potchefstroom.

Smit, MA., and De Beer, GP. (1989). Guidelines for cultivar choice. Grain Crops Research Institute, Potchefstroom.

Stander, CJ. (2012). The economics of wheat cultivar improvement research in South Africa. Unpublished MSc. Thesis. Department of Agricultural Economics, Extension and Rural Development. Faculty of Natural and Agricultural Sciences. University of Pretoria. Pretoria.

Thirtle, C., Townsend, RF., Amadi, J., Lusigi, A. \& van Zyl, J. 1998. The rate of return on expenditures of the South African Agricultural Research Council (ARC). Agrekon, 37(4): $612-622$ 